\title{
Breaking up is hard to do: the complexity of the dinoflagellate chloroplast genome
}

\author{
Adrian C. Barbrook, Christopher J. Howe* \& R. Ellen R. Nisbet \\ Department of Biochemistry, University of Cambridge, Downing Site, Tennis Court Road, Cambridge, \\ CB2 1QW, UK \\ * Corresponding author: ch26@ cam.ac.uk
}

\section{With 1 figure}

\begin{abstract}
Dinoflagellates are a diverse and widely distributed protist group, of major environmental and economic importance. Many, but not all, are photosynthetic. Many of the photosynthetic species contain a secondary chloroplast of red algal origin with peridinin as an accessory pigment. These organisms have a highly anomalous chloroplast genome that is fragmented into plasmid-like molecules and highly reduced, encoding 12 proteins involved in photosynthetic light reactions as well as rRNA and some tRNAs. Chloroplast transcripts receive 3' polyU tails, and many undergo RNA editing. Some lineages have replaced chloroplasts with others from non-dinoflagellate taxa, and in some instances the unusual processing pathways are applied to the newly acquired chloroplasts. Some non-photosynthetic lineages have lost chloroplast genomes, and others may have lost chloroplasts altogether.
\end{abstract}

Keywords: dinophyceae; coral bleaching; plastid; light reactions; photosynthetic electron transfer; endosymbiosis; organelle; CORR hypothesis; tRNA import

\section{Introduction}

Dinoflagellate algae are found in aquatic environments the world over. These remarkably diverse single-celled eukaryotic algae are key components of coral reefs, the causative agents of shellfish poisoning, and the culprits behind red tides. About half of dinoflagellate species are photosynthetic, containing a chloroplast. The majority of those contain the carotenoid peridinin as an accessory pigment. In some dinoflagellate groups the peridinin chloroplast has been lost and replaced with another from another eukaryote. For example, a number of species have a fucoxanthincontaining chloroplast derived from a haptophyte alga. Some of the non-photosynthetic species also contain a remnant chloroplast (Janouškovec et al. 2017), although at least one, Hematodinium sp., has lost the organelle completely (Gornik et al. 2015). In 1999, peridinin dinoflagellates were reported to have an extraordinary fragmented chloroplast genome (Zhang et al. 1999). We reviewed this genome in 2008 (Howe et al. 2008), but although ten years on significant progress has been made there are still many questions outstanding.

\section{Organization of the chloroplast genome}

Unlike most other photosynthetic eukaryote species, the peridinin-containing dinoflagellates do not have a conventional chloroplast genome. Instead (Fig. 1), the genome is fragmented into multiple $2-5 \mathrm{~kb}$ plasmid-like molecules, termed minicircles (Zhang et al. 1999; Barbrook \& Howe 2000). Each minicircle contains a core region, which is assumed to include an origin of replication (Nisbet et al. 2008), together with one to four genes, although one is most common. In addition, there are reports of 'empty' minicircles, which do not contain any genes, 'microcircles' (300-500 bp) and 'jumbled' circles, where recombination events have given rise to chimeric minicircles (Nisbet et al. 2004; Zhang et al. 2001).

Twelve protein coding genes have been consistently found in peridinin-containing dinoflagellate chloroplasts: atp $A$, $a t p B$, petB, petD, $p s a A, p s a B, p s b A, p s b B, p s b C, p s b D, p s b E$, and $p s b I$. In addition, sequences representing large and small subunit rRNAs are also present, although the rRNAs may be encoded as separate fragments. No other protein coding genes of plastid origin have been conclusively demonstrated in any peridinin-containing dinoflagellate chloroplast. This picture was initially formed from analyses of DNA sequences obtained by a variety of approaches (Howe et al. 2008; Barbrook et al. 2014; Dang \& Green 2009; Mungpakdee et al. 2014), and has 


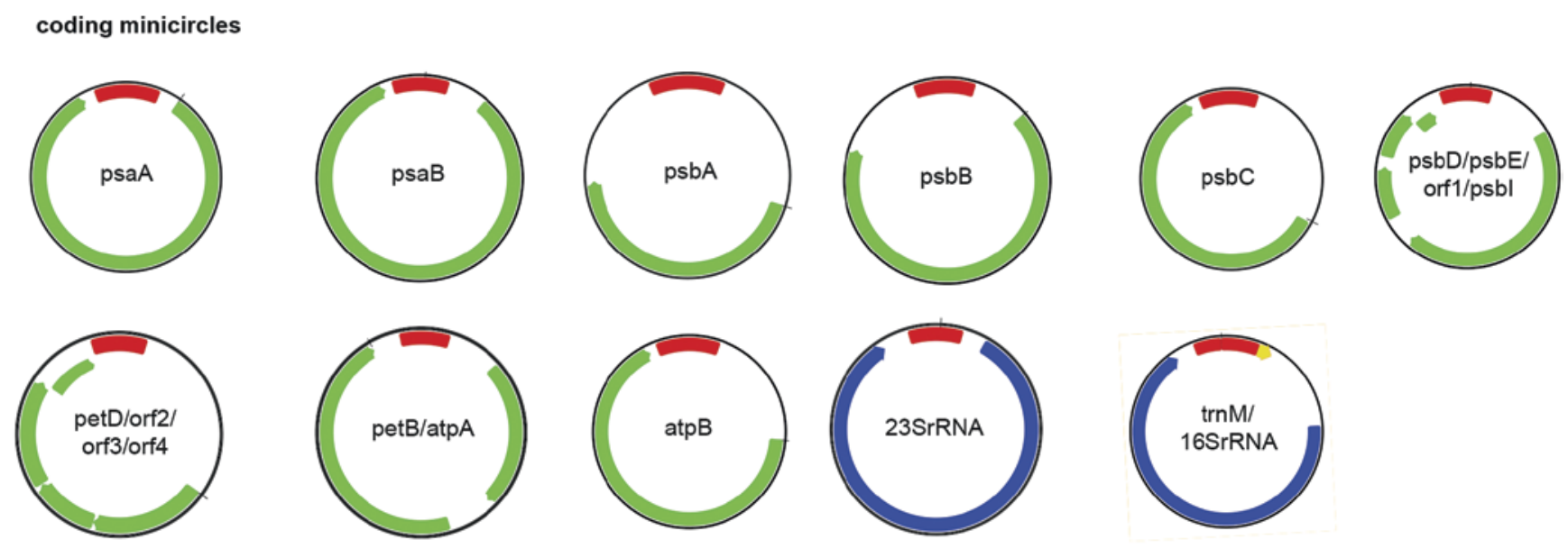

empty minicircles
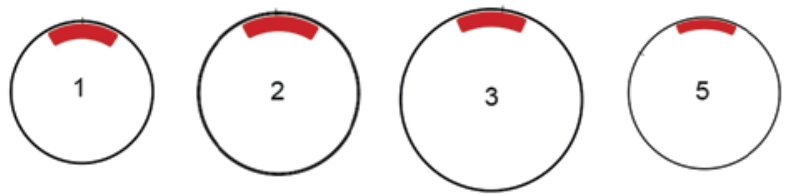

microcircles

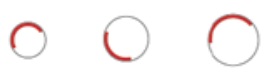

Fig. 1. The fragmented Amphidinium carterae chloroplast genome. The core region of each minicircle is shown in red, protein coding genes in green, rRNA genes in blue and the single tRNA gene in yellow. The small dash indicates position 1 in the NCBI accession for each minicircle. (Note that there is no empty minicircle 4 as it was subsequently found to encode trnM/16S rRNA). All minicircles are shown to scale.

subsequently been confirmed by analysis of extensive transcriptome resources (Dorrell et al. 2017).

Why are there only 12 protein coding genes on the chloroplast genome? Most chloroplasts contain about ten times more genes. The difficulty of providing a full set of minicircles to each daughter cell on division may have provided a strong selective advantage for the transfer of genes to the nucleus (assuming fragmentation occurred prior to the transfer of those genes). But why is this particular subset of chloroplast genes retained? The answer probably comes from the CORR (CO-location for Redox Regulation) theory which proposes that a rapid response to redox imbalances during photosynthesis requires that the genes for key components of the electron transfer chain are retained in the same intracellular compartment as the complexes themselves (Allen 2017). Consistent with CORR, these twelve genes encode the first proteins assembled into each complex in the photosynthetic electron transport chain: PsbA/PsbI and PsbD/PsbE for Photosystem II, followed by PsbC and PsbB (Heinz et al. 2016), PetB/PetD for the cytochrome $b_{6} f$ complex (Kuras \& Wollman 1994), PsaA/PsaB for Photosystem I (Yang et al. 2015), and AtpA/AtpB for ATP synthase (Schöttler et al.
2015). Although some of the proteins that are assembled into the complexes later are chloroplast-encoded in other organisms, their genes have been transferred to the nucleus in dinoflagellates.

In addition to the identified minicircle genes, genes $y c f 16$ and $y c f 24$ have been reported from minicircles in Ceratium horridum (Laatsch et al. 2004) and rpl28 and rpl33 from minicircles in Pyrocystis lunula. All four have been proposed to be derived horizontally from Bacteroidetes (Moszczynski et al. 2011). However, the chloroplast location of these sequences has been questioned, and is discussed further in Frequently asked questions below. Four other open reading frames have been located in the chloroplast DNA of $A$. carterae, designated ORF1-4 (Barbrook et al. 2012). They have been shown to give rise to processed transcripts (Barbrook et al. 2012), but are very restricted in their taxonomic distribution, as discussed in Frequently asked questions below (Dorrell et al. 2017).

In addition to the protein-coding and rRNA genes mentioned above, a small number of tRNA genes have been identified. Initial discoveries were made in Amphidinium carterae and Heterocapsa triquetra (Barbrook et al. 2006; Nelson et al. 
2007). Both species contain a putative initiator methioninetRNA gene, and $H$. triquetra also has proline- and tryptophan-tRNA genes. No tRNA genes have been identified in any of the extensively investigated Symbiodinium chloroplast genomes (Barbrook et al. 2014; Mungpakdee et al. 2014). Taken together, the observations above suggest that while the protein coding content of the chloroplast genome is effectively static and conserved, the tRNA coding content is variable.

It is interesting that in H. triquetra the tRNA genes are found in tandem arrays positioned shortly after some of the protein coding sequences. It is possible that in these cases the excision of the tRNAs from the polycistronic primary transcripts facilitates generation of the 3' end of the preceding mRNA. This would be analogous to the processing of the transcripts within the remnant chloroplast of the apicomplexan Plasmodium (Nisbet et al. 2016). In contrast, in Amphidinium carterae the initiator methionine-tRNA gene precedes the small subunit rRNA gene and in Amphidinium massartii the initiator methionine-tRNA gene is not found adjacent to any gene, though it is located on the $p s b A$ minicircle. It therefore appears that the retention of tRNA genes in the plastid, and their location relative to other genes are highly variable across dinoflagellates.

\section{Other fragmented chloroplast genomes}

There are very few examples of similar chloroplast genomes in other organisms. The chloroplast genome of the green alga Koshicola spirodelophila is fragmented into three chromosomes, although the gene content is not greatly different from other chloroplasts (Watanabe et al. 2016). In the green alga Boodlea composita (a member of the Cladophorales), and possibly also in other members of the order, the chloroplast genome is reduced to 21 protein coding genes and the $16 \mathrm{~S}$ rRNA gene. The genome is also fragmented, with the genes located on hairpin chromosomes, together with gene fragments and repetitive elements (Cortona et al. 2017). Based on the number of separate contigs, there may be as many as 34 chromosomes. All the genes found in the peridinin chloroplast genome, with the exception of those for 23S rRNA, tRNAs, and PsbI, are also found in the Boodlea chloroplast genome. In addition the latter has atpH, atpI, petA, psaC, $p s b F, p s b J, p s b K, p s b L, p s b T$ and $r b c L$ genes (Cortona et al. 2017). There is therefore a high degree of convergence in content between the genomes, suggesting a functional reason for the retention of particular genes.

\section{Location of minicircles}

For many years, there was only indirect evidence that the minicircles are indeed in the chloroplast, namely: a) the genes on minicircles are typically found in chloroplasts in other species, $b$ ) there is no N-terminal targeting sequence encoded in each minicircle gene, suggesting that the protein products are utilized in the compartment where they are synthesized, c) transcripts do not receive the polyA tail that is typical of nuclear transcripts, d) transcripts do not undergo the 5' trans-splicing characteristic of dinoflagellate nuclear transcripts (Zhang et al. 2007), and e) in situ hybridization revealed that Symbiodinium psbA transcripts were located in the chloroplast (Takishita et al. 2003). Owari et al. (2014) provided direct evidence that minicircle DNA (rather than transcripts) is located in the chloroplast, using in situ hybridization of $p s b A$ and 23S genes from Amphidinium massartii. It seems reasonable to assume that the other minicircles are located in the chloroplast.

\section{Expression of the chloroplast genome}

How are the minicircle genes transcribed? Initial studies using northern blots to study transcripts from minicircles indicated that the predominant transcripts corresponded to the expected sizes of individual genes (e.g. Barbrook et al. 2001; Wang \& Morse 2006; Dang \& Green 2010). However, northern analyses also revealed the presence of longer transcripts of low abundance (Wang \& Morse 2006; Nisbet et al. 2008; Barbrook et al. 2012), confirmed by RT-PCR (Nelson et al. 2007; Nisbet et al. 2008). These long transcripts also include the core region (Dang \& Green 2010; Barbrook et al. 2012). Even longer transcripts containing multiple copies of minicircles, and including two copies of the core region, are also present. Assuming there are no minicircles that actually contain two core regions, this indicates that minicircles undergo rolling circle transcription, where the whole minicircle is transcribed multiple times (Dang and Green 2010; Barbrook et al. 2012). Following transcription, the long primary transcripts are cleaved to give individual mRNA, tRNA or rRNA molecules.

\section{A 3' polyU tail}

Unlike the situation in plant and other algal chloroplasts, a polyU tail is added to the 3' end of protein-coding transcripts (Wang \& Morse 2006; Nelson et al. 2007). The distance of the polyU addition site from the end of the coding sequence is 4-18 nucleotides in A. carterae (and 16-20 for $p s b A$ in Lingulodinium polyedra), and the tail is between 10 and 40 nt long, or 25-40 for $p s b A$ and atpB in L. polyedra (Wang \& Morse 2006; Barbrook et al. 2012). The tail is not encoded by the minicircle, and so must be added post-trancriptionally. Analysis of transcripts for various genes in multiple species suggests some have defined positions of polyU addition but this is not always the case (Wang \& Morse 2006; Barbrook et al. 2012; Dorrell et al. 2017).

In some species, minicircles contain multiple genes, and primary transcripts are polycistronic. In $A$. carterae, polyU tails have been identified on polycistronic transcripts, both dicistronic (e.g. petD/ORF2, ORF1/psbI, petB/atpA) and tricistronic $p s b E / O R F 1 / p s b I$ (Barbrook et al. 2012). No monocistronic petD transcripts have been identified, suggesting 
that this mRNA exists only in polycistronic form. The presence of a polyU tail was used to confirm the presence of novel chloroplast ORFs in A. carterae; transcripts of ORF1, 2, 3 and 4 all gain a polyU tail (Barbrook et al. 2012).

\section{5' end processing}

For some genes, the majority of 5' UTRs are of the same length (35 nucleotides in the case of the A. carterae pet $D /$ $O R F 2$ transcripts), suggesting precise processing. However, some genes have transcripts with a range of UTRs, some of which can be hundreds of nucleotides long, e.g. $350 \mathrm{nt}$ in A. carterae psbA (Barbrook et al. 2012). Completion of processing at one end does not appear to be linked with completion of processing at the other, suggesting processing of the 5 ' and ' ' ends is independent.

\section{RNA editing}

Outside the dinoflagellates, editing of chloroplast transcripts is essentially restricted to land plants and an isolated instance in Plasmodium (Barbrook et al. 2010; Nisbet et al. 2016). Editing of chloroplast transcripts occurs in dinoflagellates, but there is considerable variation in the extent across species, and the point in dinoflagellate evolution when it arose is unclear (Janouškovec et al. 2017). Some species, such as Symbiodinium, undergo extensive RNA editing (Zauner et al. 2004; Wang \& Morse 2006; Dang \& Green 2009; Mungpakdee et al. 2014), while others, such as Amphidinium, do not undergo RNA editing (Barbrook et al. 2001). The most common edit in all species is $A-G$, accounting for about three quarters of all events. Nearly nine in ten (88\%) Symbiodinium minutum editing events result in amino acid substitutions (Mungpakdee et al. 2014).

There are several consequences of editing. In many dinoflagellate species, editing events remove premature stop codons (Mungpakdee et al. 2014; Zauner et al. 2004), or change a predicted AUA start codon to AUG (Zauner et al. 2004). Additionally, editing sites are more likely to occur in regions encoding helices from the core transmembrane proteins. Analysis of predicted protein 3D models shows that the editing tends to change properties of proteins, reducing the molecular weight and increasing hydropathy (Mungpakdee et al. 2014). Klinger et al. (2018) argued for global patterns and consequences of editing across taxa, although individual events were typically restricted to single species. Their study suggested editing helped reduce the deleterious consequences of mutations.

Editing is likely to occur late in post-transcriptional processing, as polycistronic molecules appear not to be edited but monocistronic molecules generally are. Transcripts with a polyU tail have undergone editing, indicating that editing occurs before or concomitantly with polyU addition (Dang \& Green 2009). It is unclear what the editing mechanism is, but it should be noted that dinoflagellate mitochondrial transcripts are also extensively edited (Lin et al. 2002).

\section{Replacement plastids}

The ancestral plastid, found in peridinin dinoflagellates, is of red algal origin (as reviewed by Dorrell \& Howe 2015). However, many dinoflagellate species are now non-photosynthetic, and some may have lost the plastid. Other groups of dinoflagellates have instead replaced the original chloroplast with a chloroplast (or even a whole organism, including other organelles) of haptophyte, diatom, green algal or cryptophyte origin (Waller \& Koreny 2017).

In lineages containing a chloroplast of haptophyte origin, such as Karlodinium veneficum, the chloroplast genome contains about half as many genes as chloroplasts of free-living haptophytes (Gabrielsen et al. 2011; Dorrell et al. 2016). The missing genes have either been lost or transferred to the nucleus, and the remaining gene order has been reshuffled (Gabrielsen et al. 2011). A functional minicircle containing dnaK has been identified, suggesting that genome fragmentation is occurring (Espelund et al. 2012; Richardson et al. 2014). Both RNA editing and the addition of a polyU tail are seen in these replacement chloroplasts - events that do not occur in the chloroplasts of free-living haptophytes. What is more, the pattern of editing events appears to be similar between fucoxanthin and peridinin chloroplasts. Presumably these RNA processing pathways were retained from the ancestral peridinin chloroplast and applied to the replacement chloroplast (Dorrell \& Howe 2012; Jackson et al. 2013; Richardson et 2014; Klinger et al. 2018).

In contrast, dinoflagellates containing a chloroplast of diatom origin ('dinotoms') also contain a diatom nucleus and mitochondrion (Burki et al. 2014). The chloroplast genome resembles that of a free-living diatom (Imanian et al. 2010), and there are only low levels of gene transfer to the host nucleus (Burki et al. 2014). There is no RNA editing or polyU tail addition (Richardson et al. 2014), suggesting a lower level of genetic integration with the host dinoflagellate.

Lepidodinium species contain a chloroplast of green algal origin, most likely from within the pedinophytes. The Lepidodinium chloroplast genome has 14 or so conserved genes fewer than in free-living pedinophytes (Matsumoto et al. 2011; Kamikawa et al. 2015). There is no evidence of RNA editing or polyU tails (Richardson et al. 2014).

Finally, Dinophysis and some other dinoflagellate species contain a plastid of cryptophyte origin (Park et al. 2014). There has been considerable debate as to whether this should be regarded as a permanent or transient chloroplast, often referred to as a 'kleptochloroplast' (Park et al. 2008; Garcia-Cuetos et al. 2010). Dinophysis acquires this cryptophyte chloroplast from prey, and changing the prey species results in a gradual replacement of the chloroplast to that of the new prey, strongly indicating that the chloroplast is not permanent (Raho et al. 2014). On the other hand, the chloroplast can be retained for some months in the absence of prey, and shows photoregulation of pigment production (Hansen et al. 2016), indicating a degree of sta- 
bility in the relationship (although whether photoregulation is determined by the host is not clear). It would be interesting to examine transcripts in the acquired chloroplast for the occurrence of RNA editing and addition of polyU tails, which would indicate significant integration with the host at the genetic level, as is the case in haptophyte-derived replacement dinoflagellate chloroplasts. The relationship between the chloroplast and the host is further complicated by transcriptomic evidence for a cryptic, non-photosynthetic chloroplast in Dinophysis that provides the host with essential biochemical functions (Janouškovec et al. 2017). The relationship of the two chloroplasts of Dinophysis to the host clearly merits further study.

\section{Chloroplast loss - or not?}

Only half of dinoflagellate species can carry out photosynthesis. It has long been assumed that the remaining species do not contain a chloroplast, having lost the ancestral organelle. Indeed, there is evidence for the transfer of nonphotosynthetic organelle function to the cytosol in the earlybranching parasitic species Hematodinium. This allowed for complete loss of the chloroplast in this species (Gornik et al. 2015). However, extensive transcriptomic analysis of two free-living, non-photosynthetic dinoflagellates (Oxyrrhis marina and Noctiluca scintillans) revealed the presence of several genes encoding proteins with bipartite targeting sequences, typical of that seen in proteins targeted to the chloroplast, suggesting a chloroplast had been retained (Janouškovec et al. 2017). These encode proteins in chloroplast pathways of isoprenoid and tetrapyrrole biosynthesis (Janouškovec et al. 2017). It seems highly likely that most, and possibly all, free-living non-photosynthetic dinoflagellates retain a remnant chloroplast without a genome (Janouškovec et al. 2017). The dinotoms (see above) appear to have supplemented their remnant ancestral chloroplast with a photosynthetic one of diatom origin (Hehenberger et al. 2014).

\section{Frequently asked questions}

Is there a master chloroplast chromosome, from which the minicircles are derived? Although this is an attractive idea, no evidence for a master chromosome has been detected, in Southern blotting, in searches of genome sequences (Shoguchi et al. 2013; Lin et al. 2015) or by PCR. In addition, no transcripts have been identified which contain sequences from multiple minicircles, which would be expected if a master circle were present. Furthermore, the genes that are not found on minicircles but would be expected on a conventional chloroplast genome appear to be located in the nucleus. Therefore, it seems most likely that the collection of minicircles represents the only chloroplast genome.
Are there additional minicircle genes, not yet identified? As noted above, Moszczyński et al. (2012) reported that some genes had been laterally transferred from bacteria into the dinoflagellate chloroplast (ycfl6 and $y c f 24$ in Ceratium horridum, and rpl28 and rpl33 in Pyrocystis lunula). However, a recent analysis showed that transcripts from these genes (or homologues in other dinoflagellates) did not have polyU tails, although some had a polyA tail and spliced leader sequence, indicating a nuclear localization (Dorrell et al. 2017).

The Marine Microeukaryote Transcriptome Sequencing Project (MMETSP) (Keeling et al. 2014) has provided a wealth of sequence data for marine algae. It was recently mined for further dinoflagellate sequences that could be on minicircles within the chloroplast, as indicated by the presence of a polyU tail. This approach showed that of the four ORFs in A. carterae referred to above, only three (ORFs 1-3) could be identified elsewhere. These were in another Amphidinium species, A. massartii, and were poorly conserved. Other possible plastid ORFs were also of very limited distribution (Dorrell et al. 2017). Overall, although we cannot exclude the existence of additional coding minicircles, they are likely to be limited in distribution, and the functions of their products are unknown. Their limited distribution could reflect recent acquisition, either through lateral transfer, or as novel genes generated in situ.

\section{Conclusion}

The fragmentation and reduction of the dinoflagellate chloroplast genome gave rise to a number of novel difficulties to overcome in maintaining and regulating a complete set of the remaining genes, as well as importing the proteins and RNAs whose genes were relocated to the nucleus, hence the title of this review. Although our understanding of the organisation and expression of the minicircles has improved dramatically over the last 20 years, a number of important questions remain.

a) What is the role, if any, of the empty minicircles? Do they, for example, direct the synthesis of noncoding RNAs?

b) How are replication, transcription and post-transcriptional processing controlled? Are there trans-acting factors and cis-acting sequences that are responsible? In particular, if the genome is retained to allow redox control, how is this brought about?

c) How are tRNAs imported?

d) How are minicircles partitioned during division? Does the fragmentation of the genome account for the replacement of chloroplasts in so many lineages?

e) What are the functions of the lineage-specific ORFs?

f) What caused the fragmentation of the genome in the first place? 
Having a reliable dinoflagellate chloroplast transformation system would help in answering many of these questions. Nevertheless, based on the rest of dinoflagellate biology, the answers are unlikely to be simple.

Acknowledgements: Our work is funded by the Gordon and Betty Moore Foundation through Grant GBMF4976 to CJH.

\section{References}

Allen, J.F. (2017): The CoRR hypothesis for genes in organelles. J. Theor. Biol. 434: 50-57.

Barbrook, A.C., Dorrell, R.G., Burrows, J., Plenderleith, L.J., Nisbet, R.E.R. \& Howe, C.J. (2012): Polyuridylylation and processing of transcripts from multiple gene minicircles in chloroplasts of the dinoflagellate Amphidinium carterae. - Plant Mol. Biol. 79: 347-357.

Barbrook, A.C. \& Howe, C.J. (2000): Minicircular plastid DNA in the dinoflagellate Amphidinium operculatum. - Mol. Gen. Genet. 263: 152-158.

Barbrook, A.C., Howe, C.J., Kurniawan, D.P. \& Tarr, S.J. (2010): Organization and expression of organellar genomes. - Phil. Trans. Roy. Soc. B 365: 785-797.

Barbrook, A.C., Symington, H., Nisbet, R.E., Larkum, A. \& Howe, C.J. (2001): Organisation and expression of the plastid genome of the dinoflagellate Amphidinium operculatum. - Mol. Genet. Genomics 266: 632-638.

Burki, F., Imanian, B., Hehenberger, E., Hirakawa, Y., Maruyama, S. \& Keeling, P.J. (2014): Endosymbiotic gene transfer in tertiary plastid-containing dinoflagellates. - Eukaryot. Cell 13: 246-255.

Cortona, A. Del, Leliaert, F., Bogaert, K.A., Turmel, M., Boedeker, C., Janou, J., Lopez-Bautista, J.M., Verbruggen, H., Vandepoele, K. \& De Clerck, O. (2017): The plastid genome in Cladophorales green algae is encoded by hairpin chromosomes. - Curr. Biol. 27: 3771-3782.

Dang, Y. \& Green, B.R. (2010): Long transcripts from dinoflagellate chloroplast minicircles suggest 'rolling circle' transcription. - J. Biol. Chem. 285: 5196-5203.

Dang, Y. \& Green, B.R. (2009): Substitutional editing of Heterocapsa triquetra chloroplast transcripts and a folding model for its divergent chloroplast 16S rRNA. - Gene 442: 73-80.

Dorrell, R.G., Hinksman, G.A. \& Howe, C.J. (2016): Diversity of transcripts and transcript processing forms in plastids of the dinoflagellate alga Karenia mikimotoi. - Plant Mol. Biol. 90: 233-247.

Dorrell, R.G. \& Howe, C.J. (2012): Functional remodeling of RNA processing in replacement chloroplasts by pathways retained from their predecessors. - Proc. Natl. Acad. Sci. U. S. A. 109: 18879-18884.

Dorrell, R.G. \& Howe, C.J. (2015): Integration of plastids with their hosts: Lessons learned from dinoflagellates. - Proc. Natl. Acad. Sci. U. S. A. 112: 10247-54.

Dorrell, R.G., Klinger, C.M., Newby, R.J., Butterfield, E.R., Richardson, E., Dacks, J.B., Howe, C.J., Nisbet, E.R. \& Bowler,
C. (2017): Progressive and biased divergent evolution underpins the origin and diversification of peridinin dinoflagellate plastids. - Mol. Biol. Evol. 34: 361-379.

Espelund, M., Minge, M.A., Gabrielsen, T.M., Nederbragt, A.J., Shalchian-Tabrizi, K., Otis, C., Turmel, M., Lemieux, C. \& Jakobsen, K.S., 2012. Genome fragmentation is not confined to the peridinin plastid in dinoflagellates. - PLoS One 7: e38809.

Gabrielsen, T.M., Minge, M.A., Espelund, M., Tooming-Klunderud, A., Patil, V., Nederbragt, A.J., Otis, C., Turmel, M., ShalchianTabrizi, K., Lemieux, C. \& Jakobsen, K.S. (2011): Genome evolution of a tertiary dinoflagellate plastid. - PLoS One 6: e19132.

Garcia-Cuetos, L., Moestrup, Ø., Hansen, P.J. \& Daugbjerg, N. (2010): The toxic dinoflagellate Dinophysis acuminata harbors permanent chloroplasts of cryptomonad origin, not kleptochloroplasts. - Harmful Algae 9: 25-38.

Gornik, S.G., Febrimarsa, Cassin, A.M., MacRae, J.I., Ramaprasad, A., Rchiad, Z., McConville, M.J., Bacic, A., McFadden, G.I., Pain, A. \& Waller, R.F. (2015): Endosymbiosis undone by stepwise elimination of the plastid in a parasitic dinoflagellate. Proc. Natl. Acad. Sci. U. S. A. 112: 5767-5772.

Hansen, P.J., Ojamäe, K., Berge T., Trampe E.C.L, Nielsen, L.T., Lips I. \& Kühl, M. (2016): Photoregulation in a kleptochloroplastidic dinoflagellate, Dinophysis acuta. - Frontiers in Microbiology 7: 785.

Hehenberger, E., Imanian, B., Burki, F. \& Keeling, P.J. (2014): Evidence for the retention of two evolutionary distinct plastids in dinoflagellates with diatom endosymbionts. - Genome Biol. Evol. 6: 2321-2334.

Heinz, S., Liauw, P., Nickelsen, J. \& Nowaczyk, M. (2016): Analysis of photosystem II biogenesis in cyanobacteria. Biochim. Biophys. Acta - Bioenerg. 1857: 274-287.

Howe, C.J., Nisbet, R.E.R. \& Barbrook, A.C. (2008): The remarkable chloroplast genome of dinoflagellates. - J. Exp. Bot. 59: 1035-1045.

Imanian, B., Pombert, J.-F. \& Keeling, P.J. (2010): The complete plastid genomes of the two 'dinotoms' Durinskia baltica and Kryptoperidinium foliaceum. - PLoS One 5: e10711.

Jackson, C.J., Gornik, S.G. \& Waller, R.F. (2013): A tertiary plastid gains RNA editing in its new host. - Mol. Biol. Evol. 30: 788-792.

Janouškovec, J., Gavelis, G.S., Burki, F., Dinh, D., Bachvaroff, T.R., Gornik, S.G., Bright, K.J., Imanian, B., Strom, S.L., Delwiche, C.F., Waller, R.F., Fensome, R.A., Leander, B.S., Rohwer, F.L. \& Saldarriaga, J.F. (2017): Major transitions in dinoflagellate evolution unveiled by phylotranscriptomics. Proc. Natl. Acad. Sci. U. S. A. 114: E171-E180.

Kamikawa, R., Tanifuji, G., Kawachi, M., Miyashita, H., Hashimoto, T. \& Inagaki, Y. (2015): Plastid genome-based phylogeny pinpointed the origin of the green-colored plastid in the dinoflagellate Lepidodinium chlorophorum. - Genome Biol. Evol. 7: 1133-1140.

Keeling, P.J., Burki, F., Wilcox, H.M., Allam, B., Allen, E.E., Amaral-Zettler, L.A. (....) \& Worden, A.Z. (2014): The Marine Microbial Eukaryote Transcriptome Sequencing Project (MMETSP): illuminating the functional diversity of eukaryotic life in the oceans through transcriptome sequencing. - PLoS Biol. 12: e1001889.

Klinger, C.M., Paoli, L., Newby, R.J., Wang, M.Y.-W., Carroll, H.D., Leblond, J.D., Howe, C.J., Dacks, J.B., Bowler, C., Cahoon, A.B., Dorrell, R.G. \& Richardson, E. (2018): Plastid 
transcript editing across dinoflagellate lineages shows lineagespecific application but conserved trends. - Genome Biol. Evol. 10: 1019-1038.

Kuras, R. \& Wollman, F.A. (1994): The assembly of cytochrome $b_{6} / f$ complexes: an approach using genetic transformation of the green alga Chlamydomonas reinhardtii. - EMBO J. 13: 1019-1027.

Laatsch, T., Zauner, S., Stoebe-Maier, B., Kowallki, K. \& Maier, U.-G. (2004): Plastid-derived single gene minicircles of the dinoflagellate Ceratium horridum are localized in the nucleus. Mol. Biol. Evol. 21: 1318-1322.

Lin, S., Cheng, S., Song, B., Zhong, X., Lin, X., Li, W. (....) \& Morse, D. (2015): The Symbiodinium kawagutii genome illuminates dinoflagellate gene expression and coral symbiosis. Science 350: 691-694.

Lin, S., Zhang, H., Spencer, D.F., Norman, J.E. \& Gray, M.W. (2002): Widespread and extensive editing of mitochondrial mRNAS in dinoflagellates. - J. Mol. Biol. 320: 727-739.

Matsumoto, T., Shinozaki, F., Chikuni, T., Yabuki, A., Takishita, K., Kawachi, M., Nakayama, T., Inouye, I., Hashimoto, T. \& Inagaki, Y. (2011): Green-colored plastids in the dinoflagellate genus Lepidodinium are of core chlorophyte origin. - Protist 162: 268-276.

Moszczynski, K., Mackiewicz, P. \& Bodyl, A. (2012): Evidence for horizontal gene transfer from Bacteroidetes bacteria to dinoflagellate minicircles. - Mol. Biol. Evol. 29: 887-892.

Mungpakdee, S., Shinzato, C., Takeuchi, T., Kawashima, T., Koyanagi, R., Hisata, K., Tanaka, M., Goto, H., Fujie, M., Lin, S., Satoh, N. \& Shoguchi, E. (2014): Massive gene transfer and extensive RNA editing of a symbiotic dinoflagellate plastid genome. - Genome Biol. Evol. 6: 1408-1422.

Nelson, M.J., Dang, Y., Filek, E., Zhang, Z., Yu, V.W.C., Ishida, K. $\&$ Green, B.R. (2007): Identification and transcription of transfer RNA genes in dinoflagellate plastid minicircles. - Gene 392: 291-298.

Nisbet, R.E., Hiller, R.G., Barry, E.R., Skene, P., Barbrook, A.C. \& Howe, C.J. (2008): Transcript analysis of dinoflagellate plastid gene minicircles. - Protist 159: 31-39.

Nisbet, R.E., Koumandou, L. V, Barbrook, A.C. \& Howe, C.J. (2004): Novel plastid gene minicircles in the dinoflagellate Amphidinium operculatum. - Gene 331: 141-147.

Nisbet, R.E.R., Kurniawan, D.P., Bowers, H.D. \& Howe, C.J. (2016): Transcripts in the Plasmodium apicoplat undergo cleavage at tRNAs and editing, and include antisense sequences. Protist 167: 377-388.

Owari, S., Hayashi, A. \& Ishida, K. (2014): Subcellular localization of minicircle DNA in the dinoflagellate Amphidinium massartii. - Phycol. Res. 62: 1-8.

Park, M.G., Kim, M. \& Kim, S. (2014): The acquisition of plastids/ phototrophy in heterotrophic dinoflagellates. Acta Protozoologica 53: 39-50.

Park, M.G., Park, J.S., Kim, M. \& Yih, W. (2008): Plastid dynamics during survival of Dinophysis caudata without its ciliate prey. J. Phycol. 44: 1154-1163.

Raho, N., Jaén, D., Mamán, L., Rial, P. \& Marín, I. (2014): PsbA based molecular analysis of cross-feeding experiments suggests that Dinophysis acuta does not harbour permanent plastids. Harmful Algae 35: 20-28.

Richardson, E., Dorrell, R.G. \& Howe, C.J. (2014): Genome-wide transcript profiling reveals the coevolution of plastid gene sequences and transcript processing pathways in the fucoxanthin dinoflagellate Karlodinium veneficum. - Mol. Biol. Evol. 31: 2376-2386.

Schöttler, M.A., Tóth, S.Z., Boulouis, A. \& Kahlau, S. (2015). Photosynthetic complex stoichiometry dynamics in higher plants: Biogenesis, function, and turnover of ATP synthase and the cytochrome b6f complex. - J. Exp. Bot. 66: 2373-2400.

Shoguchi, E., Shinzato, C., Kawashima, T., Gyoja, F., Mungpakdee, S., Koyanagi, R. (....) \& Satoh, N. (2013): Draft assembly of the Symbiodinium minutum nuclear genome reveals dinoflagellate gene structure. - Curr. Biol. 23: 1399-1408.

Takishita, K., Ishikura, M., Koike, K. \& Maruyama, T. (2003): Comparison of phylogenies based on nuclear-encoded SSU rDNA and plastid-encoded $p s b A$ in the symbiotic dinoflagellate genus Symbiodinium. - Phycologia 42: 285-291.

Waller, R.F. \& Kořený, L. (2017). Plastid Complexity in Dinoflagellates: A Picture of Gains, Losses, Replacements and Revisions. - In: Hirakawa, Y. (Ed.), Advances in Botanical Research. Academic Press; Oxford, UK. vol. 84, pp. 105-143.

Wang, Y. \& Morse, D. (2006): Rampant polyuridylylation of plastid gene transcripts in the dinoflagellate Lingulodinium. - Nucleic Acids Res. 34: 613-619.

Watanabe, S., Fucikova, K., Lewis, L.A. \& Lewis, P.O. (2016): Hiding in plain sight: Koshicola spirodelophila gen. et sp. nov. (Chaetopeltidales, Chlorophyceae), a novel green alga associated with the aquatic angiosperm Spirodela polyrhiza. -Am. J. Bot. 103: 865-875.

Yang, H., Liu, J., Wen, X. \& Lu, C. (2015): Molecular mechanism of photosystem I assembly in oxygenic organisms. - Biochim. Biophys. Acta. 1847: 838-848.

Zauner, S., Greilinger, D., Laatsch, T., Kowallik, K.V. \& Maier, U.G. (2004): Substitutional editing of transcripts from genes of cyanobacterial origin in the dinoflagellate Ceratium horridum. FEBS Lett. 577: 535-538.

Zhang, H., Hou, Y.B., Miranda, L., Campbell, D.A., Sturm, N.R., Gaasterland, T. \& Lin, S.J. (2007): Spliced leader RNA transsplicing in dinoflagellates. - Proc. Natl. Acad. Sci. U. S. A. 104: 4618-4623.

Zhang, Z., Cavalier-Smith, T. \& Green, B.R. (2001): A family of selfish minicircular chromosomes with jumbled chloroplast gene fragments from a dinoflagellate. - Mol. Biol. Evol. 18: $1558-1565$.

Zhang, Z., Green, B.R. \& Cavalier-Smith, T. (1999): Single gene circles in dinoflagellate chloroplast genomes. - Nature 400: $155-159$.

Manuscript received: 11.04.2018

Revisions required: 07.06.2018

Revised version received: 12.07.2018

Accepted for publication: 20.07.2018

Handling editor: Peter Kroth 